\title{
Screening for depression and associated risk factors amongst students of a government medical college in Odisha, India
}

\author{
Anandita Pattnaik ${ }^{1}$, Somy Purohit ${ }^{2}$, Dipanweeta Routray ${ }^{1}$ \\ ${ }^{1}$ Department of Community Medicine, SCB Medical College, Cuttack, Odisha. \\ ${ }^{2}$ Department of Ophthalmology, VSS Medical College, Burla, Odisha. \\ Corresponding author: Dipanweeta Routray \\ Email -drdipanweeta@gmail.com
}

\begin{abstract}
Background: Medical students are subjected to high levels of stress. Current information about the epidemiology of depression and the associated risk factors among medical students will help us in understanding its prevalence and take necessary steps to prevent it. The aim of this study is to screen for depression among the undergraduate medical students and to find out the various risk factors associated with it.

Methods: A cross sectional study was carried out in a government medical college in Odisha from November to December 2019. Screening of 902 medical students for depression and its associated factors were assessed using the 9-Item-Patient Health Questionnaire (PHQ-9) and a structured questionnaire respectively.

Result: About two third of the students (67.1\%) were found to have a certain level of depression. With regards to the severity of depression $178(19.5 \%), 59(6.5 \%)$ and $13(1.5 \%)$ students were classified as having moderate, moderately severe and severe depression respectively. The students who lacked familial or financial support, daily use of alcohol or /tobacco/usage other illicit drugs or marijuana, stress related to medical curriculum, stress due to lifestyle differences, as compared to non-medico peers and stress due to impending post graduate entrance examinations, were independently associated with depression.

Conclusion: The prevalence of moderate to severe depression among medical students in Odisha is high $(27.5 \%)$ Further evaluation and regular monitoring of such students are recommended. Adequate measures need to be taken to bring down the stress from studies and to prevent them from plummeting the path of depression.
\end{abstract}

Keywords: depression, medical students, stressors.

(Paper received $-21^{\text {st }}$ June 2020, Peer review completed $-25^{\text {th }}$ July 2020, Accepted $-28^{\text {th }}$ July 2020)

\section{INTRODUCTION}

Depression has been declared a global crisis by the WHO with a prevalence of $4.5 \%$ in the general population in India. It is the most common cause of disability as measured by Years Lived with Disability (YLDs) [1]. Medical education has a strenuous, highly demanding, and laborious curriculum which results in high stress levels among medical students [2-4]. It has been seen that medical students have a higher rate of depression than the general population [5-6]. Various studies have been conducted to assess the level and cause of depression amongst the medical students. It has been seen that the students who are academically doing well tend to be more competitive and hence, more stressed [2]. But at the same time, students who are poor in academics have been observed to be more depressed [7]. Studies have shown conflicting trends regarding depression amongst medical students starting from 1st year to final year. And some have also shown that 1st year students are more depressed due to emotional reasons (such as leaving the familiar environment of home [8], sudden exposure to extreme morbidity and mortality in the hospital setting [9], enormous study load) and difficulty in coping up $[8,10]$. While other studies have shown that final years were more depressed because of the excessive stress of the theoretical studies, clinical rotations, and preparation for competitive 
exams [9]. Students are hesitant to seek professional help in cases of mental illness as there is fear of their professional credibility being tainted and lack of their acceptance amongst the peer groups [9, 11-12]. This study was envisaged to find out the prevalence of depression among undergraduate medical students and the various correlations.

\section{METHODOLOGY}

\section{Study setting and design}

A cross-sectional anonymous questionnaire-based study was conducted from November 2019 to December 2019 at a tertiary care government teaching hospital in Odisha, after getting approval from the Institutional Ethics Committee (IEC). It included all the Bachelor of Medicine Bachelor of Surgery (MBBS) students from first to the fifth year of the college.

\section{Participants}

All the 1250 undergraduate medical students were distributed the questionnaires in their respective classrooms. They were explained in detail about the nature and purpose of the study and their participation was completely voluntary and anonymous. In order to reach out to all the students at least three visits in a span of 4 weeks were made. The students who could not be reached in the classrooms were sent the questionnaire through the class representative along with the study information sheet. The 902 students, who consented and returned the completely filled questionnaires, were considered for analysis.

\section{Questionnaire}

A self-administered questionnaire had three parts.

Part I had questions on age, gender, year of study and Patient Health Questionnaire (PHQ-9), which assisted in data collection for screening, evaluating and provisionally diagnosing depression [13-15]. Based on the PHQ-9 scores, the level of depression was assessed as minimal depression (0-4), mild depression (5-9), moderate depression (10-14), moderately severe depression (15-19), severe depression (20-27). Presence of depression was further classified as no or minimal depression (0-4) as Non-depressed and mild to severe depression (5-27) as depressed.

Part II of the questionnaire had questions to assess the presence or absence of various stressors identified after in-depth literature review [16-23]. The stressors identified and explored included lifestyle factors like daily use of alcohol or tobacco or marijuana, lack of regular exercise and yoga, stress related to medical curriculum, stress due to impending post graduate entrance examinations, stress due to lifestyle differences as compared to non-medico peers, involvement in mentally straining romantic relationships or break up within the last 6 months, lack of financial/familial support, and feelings of severe home-sickness daily for a period of more than 2 weeks.

Part III of the questionnaire had a few open-ended questions seeking suggestions from the students on how to cope up with stress and depression.

\section{STATISTICAL ANALYSIS}

Data were entered using Microsoft Excel 2010 and analyzed using Statistical Package for Social Sciences version 18 (PASW statistics for Windows, Chicago: SPSS Inc.). Descriptive statistics were used, and the results were expressed as mean \pm standard deviation or frequency and percentage. Normally distributed quantitative and categorical variables were compared using Student's t-test and Pearson $\square 2$ test respectively. The risk factors associated with lifestyle variables were dichotomized into stress due to medical curriculum (present/absent), daily use of alcohol or /tobacco/usage other illicit drugs or marijuana (present/absent), lack of regular exercise or yoga (present or absent), involvement in mentally straining romantic relationship or break up within the last 6 months, (present/absent), feelings of severe home-sickness daily for a period of more than 2 weeks. (present/absent), stress due to lifestyle differences as compared to non-medico peers (present/absent) etc. Odds ratios (OR) and 95\% confidence intervals (CI) were determined. Risk factors showing association with an $\alpha$ value of $<0.20$ in univariate analysis were considered for use in multivariate 
analysis. Adjusted odds ratio (aOR) was calculated using binary logistic regression to identify significant independent risk factors for students having moderate to severe depression. Hosmer and Lemeshow tests were used to examine the fitness of the model. Asymptotic 2-tailed p-value of $<0.05$ was considered statistically significant. The qualitative data were analyzed manually by adopting free listing of responses, domain identification, and coding of responses.

\section{RESULTS}

Out of the 1250 undergraduate students, 1098 students returned the questionnaires (response rate 87.84\%) and out of which 902 were completely filled and included in this study. There were 227, 172, 211,178, and 114 students from the 1st, 2nd, 3rd, 4th, and final years of MBBS respectively. A total of $572(63.4 \%)$ male students and $330(36.6 \%)$ female students with the mean age group $20.81( \pm 1.81)$ and $20.98( \pm 1.73)$ respectively. There were $76(8.4 \%)$ students among the participants who were regular or frequent alcohol users. A total of $588(65.2 \%)$ students practiced yoga/exercise regularly. The study showed that $67.1 \%$ $(605 / 902)$ of the students who participated in the study were provisionally diagnosed to have a certain level of depression. It comprised 39.5\% $(n=355), 19.5 \%(n=178), 6.5 \%(n=59)$, and $1.5 \%(n=13)$ suffering from mild, moderate, moderately severe, and severe depression respectively according to the PHQ-9 tool. [Table 1].

Table 1 - Characteristics of the study participants $(n=902)$

\begin{tabular}{|c|c|c|c|}
\hline Factor & & $\mathrm{N}$ & $\%$ \\
\hline \multirow[t]{2}{*}{ Gender } & Male & 572 & 63.4 \\
\hline & Female & 330 & 36.6 \\
\hline \multirow{2}{*}{ Age (Mean \pm SD) } & Male & \multicolumn{2}{|c|}{$20.81 \pm 1.81$} \\
\hline & Female & \multicolumn{2}{|c|}{$20.98 \pm 1.73$} \\
\hline \multirow[t]{5}{*}{ Year of study } & 1 & 227 & 25.2 \\
\hline & 2 & 172 & 19.1 \\
\hline & 3 & 211 & 23.4 \\
\hline & 4 & 178 & 19.7 \\
\hline & 5 & 114 & 12.6 \\
\hline \multirow{5}{*}{$\begin{array}{c}\text { Depression } \\
\text { Present } \\
\text { (PHQ9 Score) }\end{array}$} & Minimal (0-4) & 297 & 32.9 \\
\hline & Mild (5-9) & 355 & 39.4 \\
\hline & Moderate (10-14) & 178 & 19.7 \\
\hline & Moderately severe (15-19) & 59 & 6.5 \\
\hline & Severe (20-27) & 13 & 1.5 \\
\hline
\end{tabular}

Year wise assessment showed that out of the first-year students, $71.8 \%$ were depressed and there was a decreasing trend of depression as the year of medical education increased, with $60.5 \%$ of the final year students being perceived as depressed. [Figure 1].

Bivariate analysis demonstrates that a particular gender is not significantly associated with depression ( $\mathrm{p}$ value $=0.84)$. While, stressful medical curriculum has a notable association with depression $(\square 2=35.8, \mathrm{p}$ values $<0.001)$. Other than that, younger age group $(16-20$ years $)$ [ $p$ value $=0.03$ ], stress due to lifestyle differences as compared to non-medico peers ( $p$ value $<0.001$ ), involvement in mentally straining romantic relationship or break up within the last 6 months $(\mathrm{p}$ value $=0.017)$, stress due to impending post graduate entrance examinations ( $p$ value $<0.001$ ), lack of familial or financial support ( $p$ value $<0.001$ ), daily use of alcohol or /tobacco/usage other illicit drugs or marijuana, ( $\mathrm{p}$ value $<0.001$ ), feelings of severe homesickness daily for a period of more than 1 week. ( $p$ value $=0.024$ ), lack of regular exercise/yoga ( $p$ value $=0.003$ ), have a significant statistical association with moderate to severe depression. On multivariate 
Figure 1 - Year wise severity of depression among the medical students according to PHQ-9 score

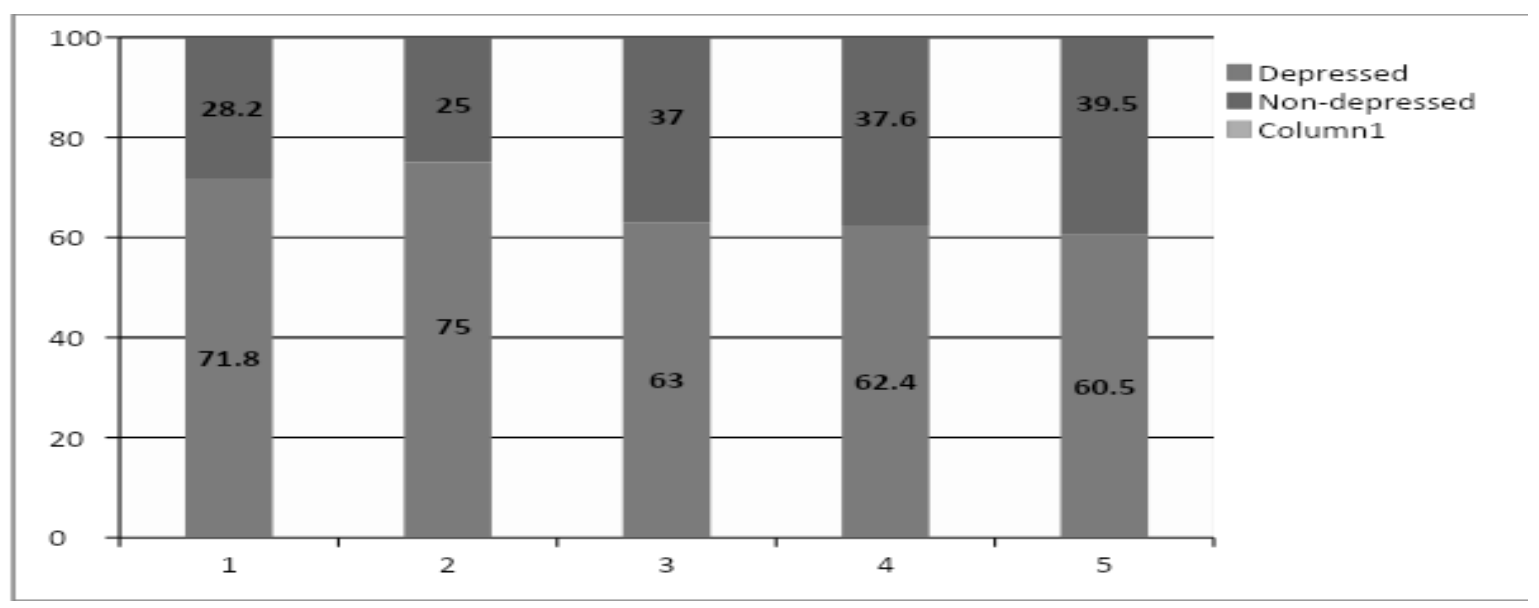

Table 2: Bivariate analysis showing the independent risk factors among the medical students associated with moderate to severe depression $(\mathrm{N}=902)$

\begin{tabular}{|c|c|c|c|c|c|c|}
\hline \multicolumn{2}{|c|}{ Characteristics } & \multirow{2}{*}{$\begin{array}{c}\text { Depressed } \\
\text { N (\%) } \\
220(66.7)\end{array}$} & \multirow{2}{*}{$\begin{array}{c}\begin{array}{c}\text { Non- } \\
\text { Depressed } \\
\text { N(\%) }\end{array} \\
110(33.3)\end{array}$} & \multirow{3}{*}{$\begin{array}{c}\begin{array}{c}\text { p-value } \\
\text { (by } \square 2 \\
\text { test) }\end{array} \\
0.844\end{array}$} & \multirow{3}{*}{$\begin{array}{c}\text { Odds Ratio (95\% } \\
\text { CI) } \\
0.97(0.73-1.3)\end{array}$} & \multirow{3}{*}{$\begin{array}{c}\begin{array}{c}\text { Adjusted OR } \\
\text { (95\% CI) }\end{array} \\
--\end{array}$} \\
\hline \multirow[t]{2}{*}{ Gender } & Female & & & & & \\
\hline & Male & $385(67.3)$ & $187(32.7)$ & & & \\
\hline \multirow[t]{2}{*}{ Age (in years) } & $17-21$ & 395 (69.7) & $172(30.3)$ & \multirow[t]{2}{*}{0.03} & \multirow[t]{2}{*}{$1.36(1.02-1.8)$} & \multirow[t]{2}{*}{$1.45(1.05-2.01)$} \\
\hline & $22-29$ & $210(62.7)$ & $125(37.3)$ & & & \\
\hline \multirow{2}{*}{$\begin{array}{l}\text { Alcohol Tobacco } \\
\text { and Other drugs* }\end{array}$} & Present & $67(85.9)$ & $11(14.1)$ & \multirow[t]{2}{*}{$<0.001$} & \multirow[t]{2}{*}{$3.14(1.63-6.04)$} & \multirow[t]{2}{*}{$3.1(1.5-6.3)$} \\
\hline & Absent & $538(65.3)$ & $286(34.7)$ & & & \\
\hline \multirow{2}{*}{$\begin{array}{l}\text { Stressful medical } \\
\text { curriculum }\end{array}$} & Present & $553(70.6)$ & $230(29.4)$ & \multirow[t]{2}{*}{$<0.001$} & \multirow[t]{2}{*}{$3.22(2.17-4.8)$} & \multirow[t]{2}{*}{$2.46(1.58-3.83)$} \\
\hline & Absent & $51(42.8)$ & $68(57.2)$ & & & \\
\hline \multirow[t]{2}{*}{ Homesickness } & Present & $376(69.9)$ & $162(30.1)$ & \multirow[t]{2}{*}{0.024} & \multirow[t]{2}{*}{$1.38(1.04-1.83)$} & \multirow[t]{2}{*}{$1.23(0.89-1.7)$} \\
\hline & Absent & $228(62.7)$ & $136(37.3)$ & & & \\
\hline \multirow{2}{*}{$\begin{array}{c}\text { PG entrance } \\
\text { exams }\end{array}$} & Present & $434(73.8)$ & $154(26.2)$ & \multirow[t]{2}{*}{$<0.001$} & \multirow[t]{2}{*}{$2.39(1.79-3.19)$} & \multirow[t]{2}{*}{$1.6(1.18-2.26)$} \\
\hline & Absent & $170(54.2)$ & $144(45.8)$ & & & \\
\hline \multirow{2}{*}{$\begin{array}{c}\text { Lifestyle } \\
\text { differences vs peers } \\
\text { (non medical) }\end{array}$} & Present & $287(74.8)$ & $97(25.2)$ & \multirow[t]{2}{*}{$<0.001$} & \multirow[t]{2}{*}{$1.88(1.40-2.51)$} & \multirow[t]{2}{*}{$1.67(1.2-2.3)$} \\
\hline & Absent & $317(61.2)$ & $201(38.8)$ & & & \\
\hline \multirow{2}{*}{$\begin{array}{l}\text { Relationship/ } \\
\text { break up }\end{array}$} & Present & $36(83.7)$ & $7(16.3)$ & \multirow[t]{2}{*}{0.017} & \multirow[t]{2}{*}{$2.63(1.15-5.98)$} & \multirow[t]{2}{*}{$1.46(0.59-3.5)$} \\
\hline & Absent & $565(66.2)$ & $289(33.8)$ & & & \\
\hline Lack of support** & Present & $46(95.8)$ & $2(4.2)$ & $<0.001$ & $11.33(2.72-$ & $10.04(2.4-43.7)$ \\
\hline & Absent & $559(65.5)$ & $295(34.5)$ & & 47.09) & \\
\hline Feels the need of & Present & $404(79.4)$ & $105(20.6)$ & $<0.001$ & $3.73(2.78-4.99)$ & $3.2(2.34-4.37)$ \\
\hline $\begin{array}{l}\text { psychiatric } \\
\text { assistance }\end{array}$ & Absent & $200(50.9)$ & $193(49.1)$ & & & \\
\hline $\begin{array}{l}\text { Lack of regular } \\
\text { Yoga/Exercise }\end{array}$ & Present & $229(73.4)$ & $83(26.6)$ & 0.003 & $1.58(1.17-2.14)$ & $1.12(0.7-1.7)$ \\
\hline
\end{tabular}


analysis and adjusting the odds ratios it was observed that daily use of alcohol or /tobacco/usage other illicit drugs or marijuana, stressful medical curriculum, stress due to impending post graduate entrance examinations, stress due to lifestyle differences as compared to non-medico peers, lack of family/financial support, significant risk factors for moderate to severe depression among medical students [Table 2].

The participants in this study who lacked proper financial or familial support were 10 times more likely to be moderate to severely depressed ( $\mathrm{aOR}=10.04,95 \% \mathrm{CI}: 2.4-43.7$ ). Those who had a history of daily use of alcohol or /tobacco/usage other illicit drugs or marijuana, had nearly 3 times increased risk of being depressed as evidenced by their adjusted odds ratios ( $\mathrm{aOR}=3.2,95 \% \mathrm{CI}: 1.5-6.3)$. While students who found the medical curriculum very stressful had almost 2.5 times increased risk of being depressed (aOR $=2.46$, 95\%CI: 1.58-3.83]). Students who were stressed due to the lifestyle differences as compared to non-medico peers such as long duration of medical education \& lack of financial independence, and were stressed due to impending post graduate entrance examinations had 1.6 times increased chances of being depressed $(\mathrm{aOR}=1.67,95 \% \mathrm{CI}: 1.2-2.3)$ and $(\mathrm{aOR}=1.6,95 \% \mathrm{CI}: 1.18-2.26)$. The younger medical students belonging to the age group of 17 to 21 years have 1.45 times increased risk of being depressed (aOR $=1.45,95 \% \mathrm{CI}$ : 1.05-2.01). A total of 56.4\% (509) students felt the need for professional help but were hesitant to seek the same. This feeling of helplessness in turn increases their risk of depression by nearly 3 times as evidenced by their adjusted odds ratios (aOR $=3.2$ [95\%CI: 2.34- 4.374)

The coping mechanisms for stress as suggested by students included formation and being a part of support groups throughout the years of medical education for proper orientation and guidance $(66.3 \%)$, formation of activity clubs like sports, music, yoga which would help act as stress busters (49.4\%), and presence of an online anonymous helpline with corroborations from departments of psychiatry \& clinical psychology in each college (15\%).

\section{DISCUSSION}

In the last decade, despite deliberate efforts made by researchers, health promoters, and social media, depression still remains largely undiagnosed and an unspoken subject in India. There is lack of awareness, empathy, and understanding not only among the general population, but also among the health care professionals. In the current study all the medical students were included in the survey and it was carried out in the month of November and December to eliminate the possibility of stress among the students due to examination in the other half of the year. The findings showed a very high overall prevalence $(67.1 \%)$ of depression among medical students, although severely depressed students comprised $1.5 \%$. Our research result was similar to that found by studies carried out in Karnataka, India and in Pakistan showing the overall prevalence of depression among medical students being $71.25 \%$ and $70 \%$ respectively [24-25]. However, research from other parts of India and western countries like Sweden, Turkey showed much lower prevalence rates of $21.5 \%, 12.9 \%$ and $29.3 \%$ respectively $[5,8,26]$. The variations in prevalence rates could be due to different tools used to screen the presence of depression, circumstances under which the studies were carried out (e.g presence of an impending examination), ethnic differences etc.

Studies done in Nepal and Turkey showed there was an increased tendency among the females to be depressed as compared to the males [27-28]. However, in our study we did not find any gender difference in the rates of depression. This was in coherence with another study done in Bhopal [29].

Current research also reveals that every three out of four, first and second year medical students were depressed; though the rate of depression tends to decrease with the increase in the years of study. This trend is similar to previous studies done $[7,24,27]$. The possible reasons could be difficulty in adjusting to a new environment, sudden increase in the amount of material to be studied and its complex nature, fatigue, pressure of making new friends, financial burden, increased expectations from medical career etc $[2,4,30]$. The latter years witness decreased rate of perceived depression due to better acclimatization to the hospital scenario and medical curriculum. Out of the various stress factors analyzed it was found that the lack of financial or familial support is the most significant predictor of moderate to severe depression. With the sudden change in mental and physical environment, adjusting to the stressful medical curriculum and being present amidst strangers can be overwhelming and extremely difficult without proper support system [3132]. 
Additionally, in the peak of youth many students suffer from emotional stress due to involvement in stressful relationships or termination of aforementioned romantic relationships affects their mental health as evidenced by the present study. Many of the students succumb to usage of alcohol, tobacco or marijuana either to deal with the various kinds of stress or due to peer pressure. Though medical students are aware of the disastrous effects of consuming alcohol, tobacco or illicit drugs on a regular basis and yet due to the poor mental health they are unable to make salubrious decisions. Previous studies have reported that students indulge in regular consumption of alcohol and other illicit drugs as a coping mechanism, of which cannabis is the most commonly abused [33-34]. This association of substance abuse with depression is quite evident from the results of this study. It is seen that those students with a history of excessive and regular use of alcohol or tobacco are 3 times more associated with depression. But a cause-effect relationship cannot be established.

Comparative differences in lifestyles such as earlier graduation and attainment of financial independence among non-medico peers is another reason for the depression among the medical students. This is supported by the findings of the present study where students who are jealous of their non-medical peers are nearly 1.7 times more likely to be depressed as compared to the students who are not. Excessive worrying about entrance exams, career specialization, and unfruitful competitiveness intensifies the risk of depression. Students also feel helpless because despite their dire need of proper counseling and psychiatric help they are unable to seek help because of the stigma associated with mental health and the way it is perceived by the society [11, 35-36].

We suggest a proper support system for the orientation of medical students about the curriculum. This support system would consist of seniors, peers and psychiatric professionals. It would help in the process of acclimatization and guide them in a beneficial manner all through the years of medical education. Implementation of this support system could help prevent, detect and treat depression as well as reduce the stigma associated with it. In addition, an anonymous online web/app-based college helpline that would allow the students, who are reluctant to reveal their identity, to seek help $24 \times 7$ in the form of online chat sessions or telephonic conversations with professional psychotherapists.

In addition, the students also felt that incorporation of yoga, meditation, and sports as compulsory elements to the medical curriculum could help improve mental health, as they have a proven benefit in reducing the levels of anxiety, stress and thereby depression in students [38-39]. Further evaluation and regular monitoring of such students are recommended. Qualitative research should be carried out to explore in depth about the underlying causes of stress and depression among these students.

This was a cross-sectional, self-reported anonymous questionnaire-based survey. Therefore, there is a potential for reporting bias either due to improper responses or because of inaccurate interpretation of the questions by the students. Extrapolation of the study results to all the medical students is limited by the characteristics of the sample which consists of students from only a single government medical college of India. Also, PHQ-9 is a screening tool for depression and it is not diagnostic and further clinical evaluation is required for a definitive diagnosis of depression. Other limitations include lack of baseline information concerning mental health of students at the time of joining the medical college and a lack of populationbased data to support our results and to compare our findings with the general population.

\section{REFERENCES}

1. World Health Organization. Depression and other common mental disorders: global health estimates. World Health Organization; 2017.

2. Supe AN. A study of stress in medical students at Seth GS Medical College. J Postgrad Med 1998;44(1):3-8.

3. Stewart SM, Betson C, Marshall I, Wong CM, Lee PW, Lam TH. Stress and vulnerability in medical students. Med Educ 1995;29(2):119-27.

4. Firth J. Levels and sources of stress in medical students. Br Med J 1986;292(6529):1177-80.

5. Dahlin M, Joneborg N, Runeson B. Stress and depression among medical students: A cross-sectional study. Med Educ 2005;39(6):594-604.

6. Dyrbye LN, Thomas MR, Shanafelt TD. Systematic review of depression, anxiety, and other indicators of psychological distress among US and Canadian medical students. Acad Med 2006;81(4):354-73.

7. Inam SN, Saqib A, Alam E. Prevalence of anxiety and depression among medical students of private university. J Pak Med Assoc 2003;53(2):44-6. 
8. Sidana S, Kishore J, Ghosh V, Gulati D, Jiloha RC, Anand T. Prevalence of depression in students of a medical college in New Delhi: a cross-sectional study. Australasian Med J 2012;5(5):247-53.

9. Rosenthal JM, Okie S. White coat, mood indigo-depression in medical school. New Engl J Med 2005;353(11):1085-90.

10. Singh A, Lal A, Singh S. Prevalence of depression among medical students of a private medical college in India. Online J Health Allied Sci 2011;9(4).

11. Tjia J, Givens JL, Shea JA. Factors associated with undertreatment of medical student depression. J Am Coll Health 2005;53(5):219-24.

12. Schwenk TL, Davis L, Wimsatt LA. Depression, stigma, and suicidal ideation in medical students. JAMA 2010;304(11):1181-90.

13. Rotenstein LS, Ramos MA, Torre M, Segal JB, Peluso MJ, Guille C, Sen S, Mata DA. Prevalence of depression, depressive symptoms, and suicidal ideation among medical students: a systematic review and meta-analysis. JAMA 2016;316(21):2214-36.

14. Adewuya AO, Ola BA, Afolabi OO. Validity of the patient health questionnaire (PHQ-9) as a screening tool for depression amongst Nigerian university students. J Affect Disord 2006;96(1-2):89-93.

15. Kroenke K, Spitzer RL. The PHQ-9: a new depression diagnostic and severity measure. Psychiatr Ann 2002;32(9):509-15.

16. Deykin EY, Levy JC, Wells V. Adolescent depression, alcohol and drug abuse. Am j Pub Health 1987;77(2):178-82.

17. Dimeo F, Bauer M, Varahram I, Proest G, Halter U. Benefits from aerobic exercise in patients with major depression: a pilot study. Br J Sports Med 2001;35(2):114-7.

18. Woolery A, Myers H, Sternlieb B, Zeltzer L. A yoga intervention for young adults with elevated symptoms of depression. Altern Ther Health Med 2004;10(2):60-3.

19. Javnbakht M, Kenari RH, Ghasemi M. Effects of yoga on depression and anxiety of women. Complement Ther Clin Pract 2009;15(2):102-4.

20. Gurung R, Sarason B, Sarason I. Close personal relationships and health outcomes: A key to the role of social support. Handbook of personal relationships: Theory, research and interventions (2nd ed) Chichester, UK: Wiley. 1997:547-73.

21. Verschuur MJ, Eurelings-Bontekoe EH, Spinhoven P. Associations among homesickness, anger, anxiety, and depression. Psychol Rep 2004;94(3_suppl):1155-70.

22. Walker III JV, Peterson GW. Career thoughts, indecision, and depression: Implications for mental health assessment in career counseling. J Career Assess 2012;20(4):497-506.

23. Becker JL, Milad MP, Klock SC. Burnout, depression, and career satisfaction: cross-sectional study of obstetrics and gynecology residents. Am J Obstetr Gynecol 2006;195(5):1444-9.

24. Kumar GS, Jain A, Hegde S. Prevalence of depression and its associated factors using Beck Depression Inventory among students of a medical college in Karnataka. Indian J Psychiatry 2012;54(3):223-8.

25. Khan MS, Mahmood S, Badshah A, Ali SU, Jamal Y. Prevalence of depression, anxiety and their associated factors among medical students in Karachi, Pakistan. J Pak Med Assoc 2006;56(12):583-8.

26. Karaoglu N, Şeker M. Anxiety and depression in medical students related to desire for and expectations from a medical career. West Indian Med J 2010;59(2):196-202.

27. Ediz B, Ozcakir A, Bilgel N. Depression and anxiety among medical students: Examining scores of the beck depression and anxiety inventory and the depression anxiety and stress scale with student characteristics. Cogent Psychol 2017;4(1):1283829.

28. Basnet B, Jaiswal M, Adhikari B, Shyangwa PM. Depression among undergraduate medical students. Kathmandu Univ Med J 2012;10(3):56-9.

29. Sharma A, Gupta SK, Khare N, Agarwal SS. Assessment of depression among medical students of private university in Bhopal, India. Subs Abuse 2015;5:12-8.

30. Mitchell RE, Matthews JR, Grandy TG, Lupo JV. The question of stress among first-year medical students. J Med Educ 1983;58(5):367-72.

31. Fadem B, Schuchman M, Simring SS. The relationship between parental income and academic performance of medical students. Acad Med 1995;70(12):1142-4.

32. Rospenda KM, Halpert J, Richman JA. Effects of social support on medical students' performances. Acad Med 1994;69(6):496-500.

33. Ashton $\mathrm{CH}$, Kamali F. Personality, lifestyles, alcohol and drug consumption in a sample of British medical students. Med Educ 1995;29(3):187-92.

34. Ball S, Bax A. Self-care in medical education: effectiveness of health-habits interventions for first-year medical students. Acad Med 2002;77(9):911-7. 
35. Chew-Graham CA, Rogers A, Yassin N. 'I wouldn't want it on my CV or their records': medical students' experiences of help-seeking for mental health problems. Med Educ 2003;37(10):873-80.

36. Givens JL, Tjia J. Depressed medical students' use of mental health services and barriers to use. Acad Med 2002;77(9):918-21.

37. Skowronek IB, Mounsey AL, Handler L. Can yoga reduce symptoms of anxiety and depression ?. J Fam Pract 2014;16(7):398-407.

38. Woolery A, Myers H, Sternlieb B, Zeltzer L. A yoga intervention for young adults with elevated symptoms of depression. Altern Ther Health Med 2004;10(2):60-3.

Acknowledgements - We like to thank all students who participated wholeheartedly in the study.

Conflict of Interest - Nil

Funding - Nil 